 \\ CONF-9305/34--5 \\ F9S05-91ER 14180
}

\author{
APPENDIX $\mathbf{J}$ \\ "Application of Hysteresis Modeling to Magnetic Techniques \\ for Monitoring Biaxial Stress"
}

M.J. Sablik, G.L. Burkhardt, and H. Kwun

(Proc. Eleventh Symposium on Energy Engineering Sciences, Argonne, IL (CONF-9305134, DOE, 1993)) 


\section{DISCLAIMER}

This report was prepared as an account of work sponsored by an agency of the United States Goverament. Neither the United States Governmeat nor any agency thereof, nor any of their employees, makes any warranty, express or implied, or assumes any legal liability or responsibility for the accuracy, compieteness, or usefuiness of any information, apparatus, product, or process disclosed. or represents that its use would not infringe privately owned rights. Refereace berein to any specific commercial product, process, or service by trade aame, trademark inanufacturer. or otherwise does not necessarily constitute or imply its endorsement, recommendation, or favoring by the United States Governmeat or any agency thereof. The views and opinions of authors expressed herein do not necessarily suate or reflect those of the United States Governmeat or any agency thereof. 


\section{DISCLAIMER}

Portions of this document may be illegible in electronic image products. Images are produced from the best available original document. 


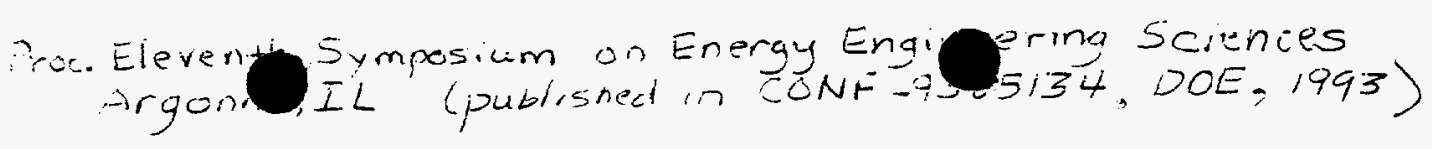

\title{
APPLICATION OF HYSTERESIS MODELING TO MAGNETIC TECHNIQUES FOR MONITORING BIAXIAL STRESS
}

\author{
M. J. Sablik. G.L. Burkhardt. and H. Kwun \\ Southwest Research Institute \\ P.O. Drawer 28510 \\ San Antonio, TX 78228-0510
}

\begin{abstract}
A probe. consisting of two excitation coils and a detection coil wrapped around a core with a Hall probe between the pole pieces, has been used to measure indirectly the influence of biaxial stress on the magnetic properties of a ferromagnetic specimen. in this case annealed SAE-4130 steel. Properties measured indirectly included remanence. coercivity, and first, third and fifth harmonic amplitudes. The properties were extracted from the voltage measured across the detection coil and incorporate the magnetic influence of the soft iron core. but with the effect of air gap variation between pole piece and sample kept to a controlled range. Results were compared to a micromagnetic model for the effect of biaxial stress on hysteresis and on magnetic properties. The micromagnetic model is a modified version of a model previously employed by Schneider et al. The experimental remanence variation due to biaxial stress compared very well to the predictions of the model. Furthermore. the model predicts, and experiment bears out, that the remanence with the field along one stress axis minus the remanence with the field along the other stress axis falls in a straight-line band of values when plotted against the difference of the two stresses. This suggests a possible NDE technique for detecting differences in biaxial stresses at a given location in a steel specimen.
\end{abstract}

\section{INTRODUCTION}

The effects of biaxial stress on magnetic properties is important to understand if one is to use magnetic NDE techniques for detecting stress in pipeline. Stress in pipeline consists of perpendicularly acting biaxial stresses, namely circumferential stress about the pipe and longitudinal stress along the length of the pipe. The magnetic properties of a steel pipeline at a given location will be affected by both stresses, longitudinal and circumferential. Thus, if one is to use in pipeline a magnetic nondestructive evaluation (NDE) stress detection technique, one needs to first understand the precise way in which biaxial stresses affect magnetic properties.

Stress in pipeline is caused by internal pressure in combination with stress from external pipeline conditions. In very cold climates, such as in Alaska, the ground freezes and thaws and in the process, the resulting ground movement exerts great stress on pipeline. In regions such as in California, where there is often sudden crustal plate motion along faults, ground movement can again produce great stresses on pipeline. Ground settling in swamplands such as Louisiana and desert sand motion such as in Saudi Arabia can often expose pipeline and cause stresses on the pipeline owing to its own weight. Silt motion at bay bottoms can also expose pipeline and even set up a situation where a pipeline might snag a passing ship. All of these situations could lead to pipeline rupture and need to be detected before the danger becomes reality.

Thus, it is important from an energy engineering point of view, to protect against high stress conditions in pipeline and to monitor biaxial stresses in pipeline. The purpose of the present study is to develop 
an understanding of the $\mathrm{Ay}$ in which biaxial stresses affect magnetrc properties so that magnetic NDE techniques can be utilized in monitoring stress in pipeline.

This paper represents a progress report for an ongoing study of the effect of biaxial stresses on various magnetic properties in steels. It is basically divided into two sections - (1) experimental work and (2) theoretical work confirming experimental observations.

Experimental results in mild steel on the effect of biaxial stress on hysteresis loop parameters were studied recently by Langman.[1] However, discussion was restricted to equal biaxial stresses. Other researchers have studied biaxial stress effects on various magnetic properties[2-5], but to date, there has not been a systematic study presented on variation of d.c. hysteresis parameters under general, unequal biaxial stress conditions. This paper in part addresses that.

Theoretical models for the effects of biaxial stress on magnetic properties have been published by Schneider et al[6] and by Kashiwaya[7]. In this paper, we modify Schneider's micromagnetic model for biaxial stress effects by borrowing some ideas from Kashiwaya, but modifying those ideas so that a better description of biaxial tensile effects on magnetic properties is possible.

\section{EXPERIMENTAL MEASUREMENTS}

The biaxial loading apparatus is shown in Fig. 1. It is designed so as to exert stresses independently along two perpendicular axes. The stresses are exerted on a cruciform (cross-shaped) specimen. The central region of the specimen experiences the effect of biaxial stresses.

The specimen used was made of SAE-4340 steel and was 0.2 " thick in the central region. At the end of each arm, the specimen was 0.4 " thick. Also, in the 0.4 " thick portion, a 0.75 " diameter hole was drilled for attachment to a pin in the biaxial stress fixture. Each arm was 1.5 " wide and 2.25 " long and the central region of the specimen would have been $1.5^{\prime \prime}$ square, except that, to smooth out the corners, a $90^{\circ}$ circular arc of 0.5 " radius of curvature was cut tangent to the arm edges joined by the arc. The specimen was chamfered where it changed from 0.2 " to 0.4 " thick at a place 1.5 " away from the arm end.

A finite element study showed that under $1: 1$ load conditions, the ratio of perpendicular stresses $\sigma_{2}: \sigma_{1}$ varied from 1.08 to 0.92 in a center region that was 0.75 " square. Thus, under a 1:1 load condition, the stresses in the center were uniform to $\pm 8 \%$. Our probe was designed to fit across that region with a distance of 0.6 " between pole centers. Thus, we could expect a maximum error of the order of less than $\pm 8 \%$ owing to the slight nonuniformity of the stress distribution.

A diagram of the sensor probe is seen in Fig. 2. The sensor consisted of excitation coils wound about both arms of a C-core, and a detection coil wound tightly at the end of one of the arms. The coils were held in place by a plastic fixture, which also held a Hall probe centered between the pole pieces and close to the sample surface. Pole piece ends and plastic fixture were all carefully machined so as to be flush against the specimen surface. A weight was then placed on top of the probe so as to press the probe against the specimen surface, and thereby minimize variations in liftoff from the specimen surface.

A second plastic fixture was designed to allow the probe to be rotated into one of three fixed position: $0^{\circ}, 45^{\circ}$, and $90^{\circ}$. Thus, a magnetic field would be generated by the probe excitation coils in one of three directions - parallel to the $\sigma_{2}$-axis, parallel to the $\sigma_{1}$-axis, or at $45^{\circ}$ with respect to either of the two stress axes.

The experiment performed was to hold the magnetic field fixed in each of the three positions $\left(0^{\circ}, 45^{\circ}, 90^{\circ}\right)$ while varying the biaxial stresses in 16 combinations per position $\left(\sigma_{1}=0,70,140,210 \mathrm{MPa}\right.$; $\sigma_{2}=0,70,140,210 \mathrm{MPa}$ ) [Note: $6.9 \mathrm{MPa}=1 \mathrm{ksi}$, and, further, positive stress is tensile stress].

For each field alignment and each stress combination, a hysteresis loop was taken using a quasi d.c. signal of $5 \mathrm{~Hz}$. From the loop were extracted values for $\mathrm{B}_{\mathrm{r}}$ (remanence), $\mathrm{H}_{\mathrm{c}}$ (coercivity), and harmonic amplitudes $A_{1}, A_{3}$ and $A_{5}$, using appropriate instrumentation. 


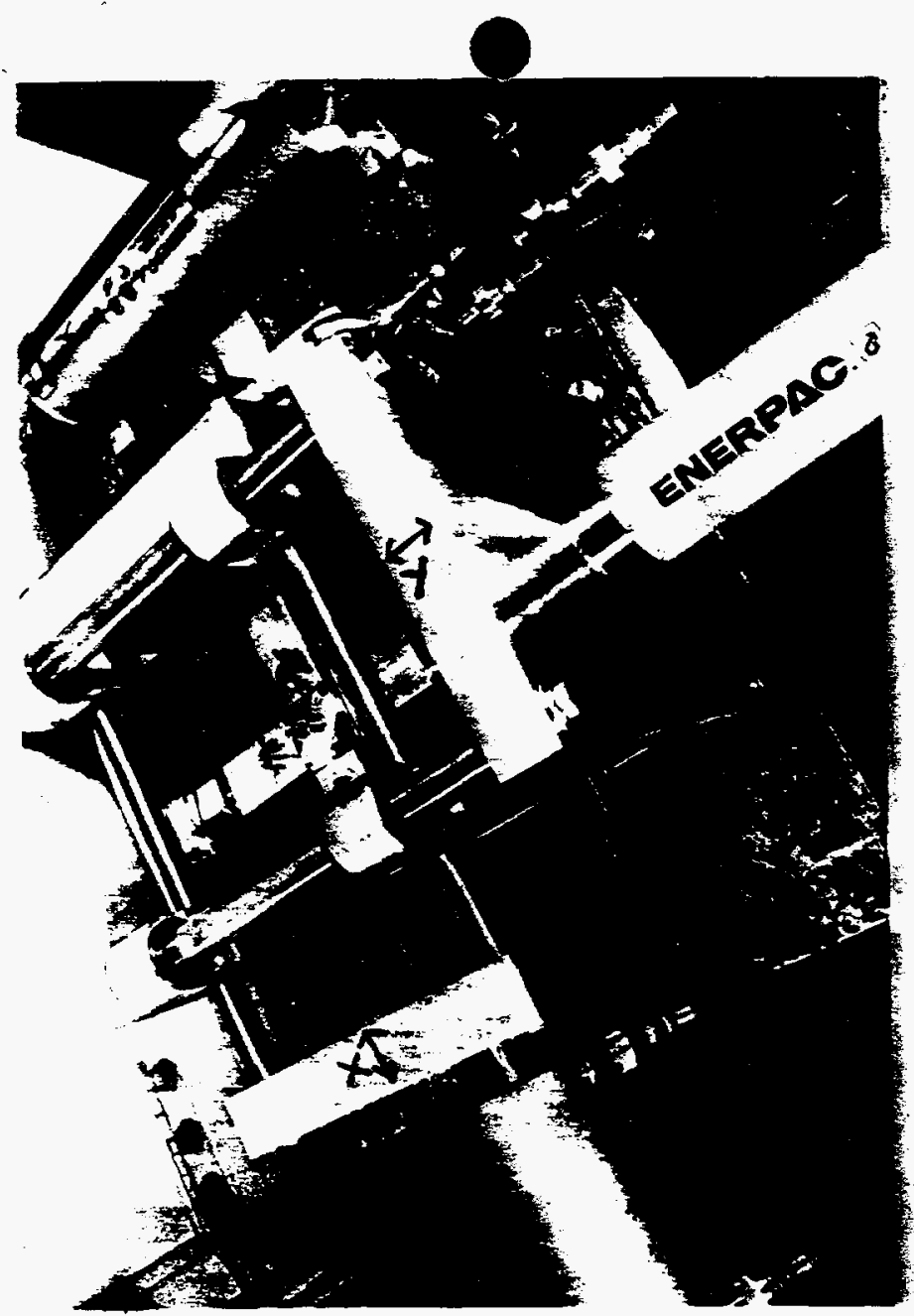

Figure 1. Photograph of biaxial stress fixture. Cruciform specimen (not visible) is in the fixture held by clamps. The sensor probe on the surface of the specimen is obscured by a plastic fixture.

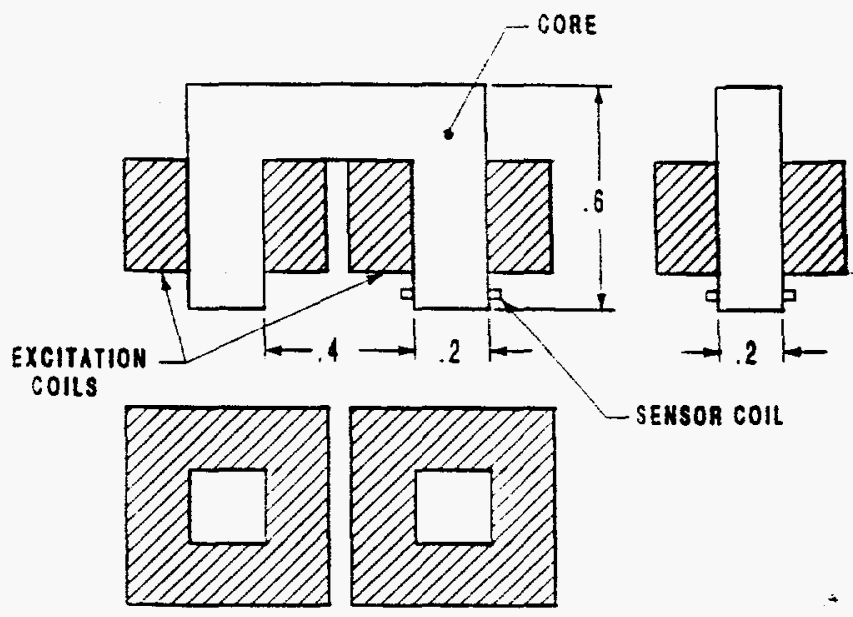

Figure 2. Diagram of the basic components of sensor probe. (Dimensions in inches).

Repeat measurements indicated a possible range of uncertainty in the measurements of $\pm 6 \%$, in the worst case. Most of this seemed to be due to liftoff variations despite efforts to minimize liftoff variation.

Experimental results will be discussed after presentation of the theoretical model.

THEORETICAL MODEL

A discussion of the basic micromagnetic model used by Schneider et al may be found in Ref. 8 . In that model, the change in magnetization $\Delta \mathrm{M}$ at the end of a process in which magnetic field $\mathrm{H}$ or stress $\sigma$ varies is

$$
\Delta M=\sum_{i} \int f_{i} \chi\left(H_{i}\right) d H_{i},
$$

where the sum $i$ is over domains with magnetization oriented in different directions. There are a finite number of different domains to consider in single crystals and a very large number to consider in polycrystals. The weight factor $f_{i}$ is an appropriate weight factor for each domain, which for polycrystals is equivalent to different $\cos \theta_{\mathrm{i}}$ for equally spaced $\theta_{\mathrm{i}}$. The $\chi\left(\mathrm{H}_{\mathrm{i}}\right)$ is the magnetic susceptibility $\mathrm{dM} / \mathrm{d} \mathrm{H}_{\mathrm{i}}$ associated with change $\mathrm{dH}_{i}$ in internal field $\mathrm{H}_{\mathrm{i}}$, which is computed from 


$$
H_{i}=H-\left(3 \lambda_{s} \sigma \cos \theta_{i} / B_{s}\right)-D_{\sigma} M \text {. }
$$

where the middle term is the stress contribution $\mathrm{H}_{\sigma}$ to the internal field and $-\mathrm{D}_{\sigma} \mathrm{M}$ is the stress demagnetization contribution. $D_{\sigma}$ is a function of stress which behaves as in Fig. 1 of Ref. 8. In eq. (2), $\lambda_{s}$ is the saturation magnetostriction, $B_{s}$ is the saturation flux density, and $D_{\sigma}$ is the stress demagnetization factor.

In eq. (1), the susceptibility $\chi\left(\mathrm{H}_{\mathrm{i}}\right)=\mathrm{dM} / \mathrm{dH}_{\mathrm{i}}$ can be obtained from the equation

$$
\chi^{-1}\left(H_{i}\right)=\chi^{-1}(H)-D_{a}
$$

and the change $\mathrm{dH}_{\mathrm{i}}$ can be obtained from

$$
d H_{\mathrm{i}}=d H /\left(1+\chi\left(H_{i}\right) D_{\sigma}\right)
$$

for processes in which $\mathrm{H}$ varies while $\sigma$ is held constant, or from

$$
d H_{i}=\frac{d \sigma\left[3\left(\lambda_{s} / B_{s}\right) \cos \theta_{i}\right]}{\left(1+\chi\left(H_{i}\right) D_{a}\right)}
$$

for processes in which $\sigma$ varies while $H$ is held constant. The reader is referred to Ref. 8 for details.

Schneider and Richardson[6], in treating biaxial stress effects, asserted that the above model may be still used, but with $\sigma$ replaced by $\sigma_{\text {eff }}=\sigma_{1}-\sigma_{2}$ and d $\sigma$ by $d \sigma_{\text {eff }}=d \sigma_{1}-d \sigma_{2}$ in the case where $H$ is parallel to the $\sigma_{1}$-axis, and by $\sigma_{2}-\sigma_{1}$ and $d \sigma_{2}-d \sigma_{1}$ respectively when $H$ is parallel to the $\sigma_{2}$-axis. This, however, does not prove to be satisfactory.

Kashiwaya[7] proposed a formalism which in effect would require that $\sigma$ be replaced by either $\sigma_{\text {eff }}$ $=\sigma_{1}-\sigma_{\max }$ or $\sigma_{\mathrm{eff}}=\sigma_{2}-\sigma_{\max }$, depending on the field direction, where $\sigma_{\max }$ is the larger of the two stresses. This would require that $\sigma_{\text {eff }} \leq 0$ and that if $\sigma_{\max }=\sigma_{2}$, then with $\mathrm{H}$ pointed along the $\sigma_{2}$-axis, $\sigma_{2}$ has no magnetic effect regardless of its value. This is a bit extreme. For a polycrystal, it is found from the Schneider formalism that the contribution from $\mathrm{H}_{\sigma}=-3 \lambda_{\mathrm{s}} \sigma_{\text {eff }} \cos \theta_{\mathrm{l}} / \mathrm{B}_{\mathrm{s}}$ tends to average out over all domains $i$ as $H$ is varied with $\sigma_{\text {eff }}$ constant and that the dominant contribution to $\Delta \mathrm{M}$ is from the demagnetization term $-D_{\sigma}\left(\sigma_{\text {eff }}\right) M$ in the internal field. For positive values of $\sigma_{\text {eff }}, D_{\sigma}\left(\sigma_{\text {eff }}\right)$ is very small but finite, staying approximately constant between 0 and $100 \mathrm{MPa}$, and then becoming larger but at a slower rate than is found at negative stresses.[8]

Thus, for positive $\sigma_{\text {eff, }}$, it is found at effective stress values $\sigma_{\text {eff }} \leq 100 \mathrm{MPa}$, there is little change in the magnetic properties, in agreement with Kashiwaya's general predictions, but that for $\sigma_{\text {eff }}>100 \mathrm{MPa}$, there begins to be found a noticeable change in magnetic properties. The key therefore is to find an appropriate expression for $\sigma_{\text {eff. }}$

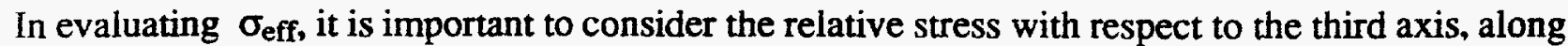
which there is no stress. Thus, the magnetic properties are affected by relative stresses with respect to all the axes. Since compression tends to push moments away from the stress axis and tension tends to pull moments toward the stress axis, one should also expect that the magnetic properties would be affected differently depending on whether the field is parallel to an axis of tension or compression. Thus, if the field is parallel to the $\sigma_{1}$-axis, and $\sigma_{1}$ is compressive (i.e. negative), then $\sigma_{\text {eff }}=(1 / 2)\left[\left(\sigma_{1}-\sigma_{2}\right)+\sigma_{1}\right]$. In other words, with field parallel to the $\sigma_{1}$-axis and with $\sigma_{1}$ compressive, the effective stress contributing to magnetic properties is the average of the relative stresses with respect to the other two orthogonal directions (viz. $\sigma_{1}-\sigma_{2}$ and $\sigma_{1}-0$ ). On the other hand, if $\sigma_{1}$ is tensile (i.e. positive), then from relative stress $\sigma_{1}-\sigma_{2}$, one subtracts off the relative stress between the $\sigma_{2}$-axis and the perpendicular zero stress axis. Thus, for tensile $\sigma_{1}, \sigma_{\text {eff }}=(1 / 2)$ $\left[\left(\sigma_{1}-\sigma_{2}\right)-\sigma_{2}\right]$. With $\sigma_{2}=0$, then $\sigma_{\text {eff }}=\sigma_{1}$ and with $\sigma_{1}=0$, then $\sigma_{\text {eff }}=-\sigma_{2}$, in accordance with what is 
known about uniaxial stress[8]. Making the above substitutions for $\sigma_{\text {eff }}$ into the Schneider model constitutes the new micromagnetic model for biaxial stress.

\section{RESULTS}

In this section, experimental resuits are compared to theoretical results. Just as experimental magnetic parameters were extracted from experimental hysteresis loops, modeling results for magnetic parameters were obtained from hysteresis loops generated by the model.

We present here only results for remanence $B_{r}$. Since the experimental changes in $B_{r}$ due to stress are scaled by the additional contribution to $\mathrm{B}_{\mathrm{r}}$ due to the probe core, it was found necessary to compare normalized results for experiment and theory. Fig. 3 shows results for $B_{r} / B_{r}(0,0)$ vs. $\sigma_{1}$, where $B_{r}(0,0)$ is $B_{r}$ for $\sigma_{1}$ $=0$ and $\sigma_{2}=0$, and where $H$ is parallel to the $\sigma_{1}$-axis. Four plots are shown, each for a different $\sigma_{2}$. The fit between experimental points $(x)$ and modeling results $(0)$ can be tuned by scaling the variation of $D_{\sigma}$ with $\sigma_{\text {eff }}$ (from Fig. 1 of Ref. 8) by a constant factor. It is seen that a very good fit is indeed attainable. Using the same scaling for $D_{\sigma}$ with $\sigma_{\text {eff }}$, Fig. 4 displays $B_{r} / B_{r}(0,0)$ vs. $\sigma_{1}$ for $H$ parallel to the $\sigma_{2}$-axis for both model and experiment. Since the new experimental results have some liftoff error built in, the fit between experiment and model is still good, but not quite as good as in Fig. 3.

$B_{r} / B_{r}(0,0)$

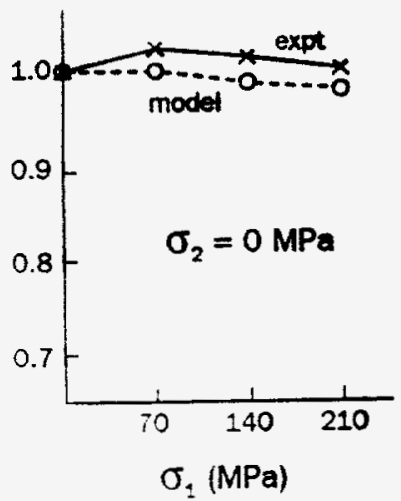

$B_{r} / B_{r}(0,0)$

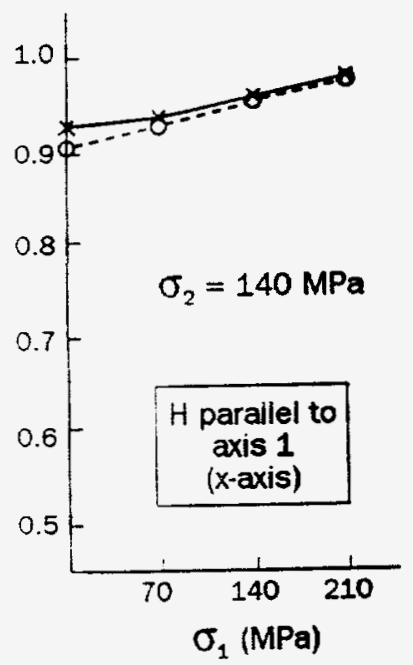

$B_{r} / B_{r}(0,0)$

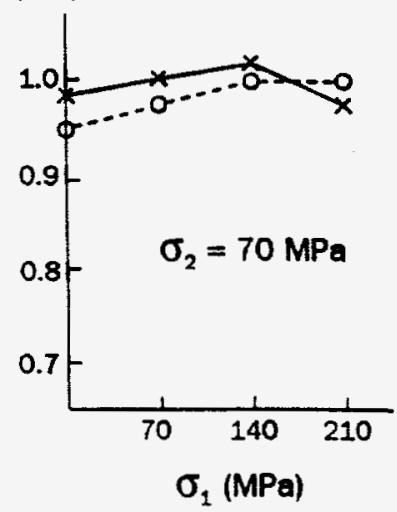

$B_{r} / B_{r}(0,0)$

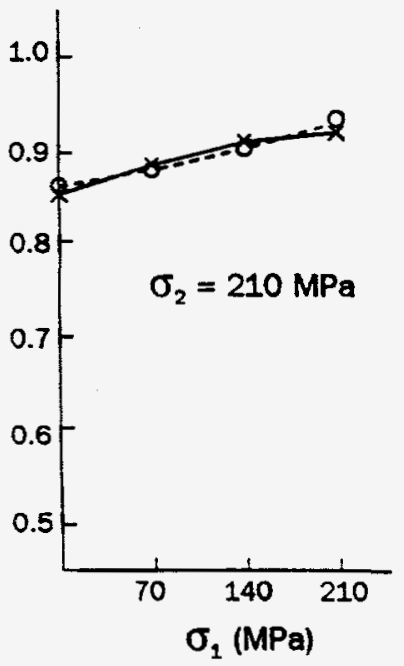

$B_{r} / B_{r}(0,0)$

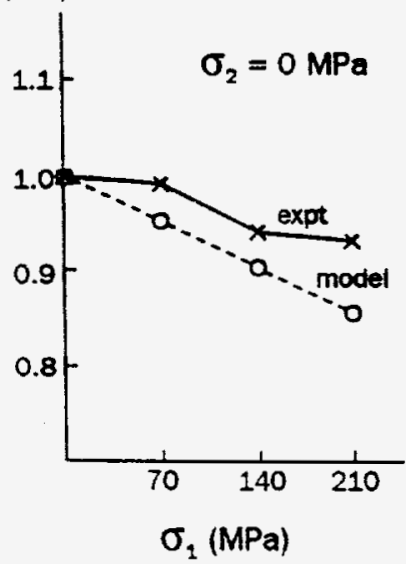

$B_{p} / B_{r}(0,0)$

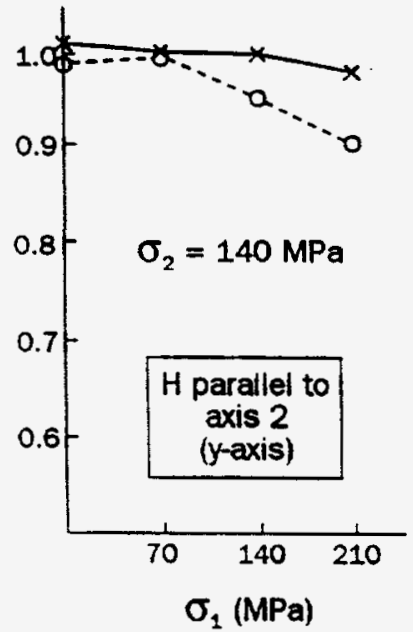

$B_{r} / B_{r}(0,0)$
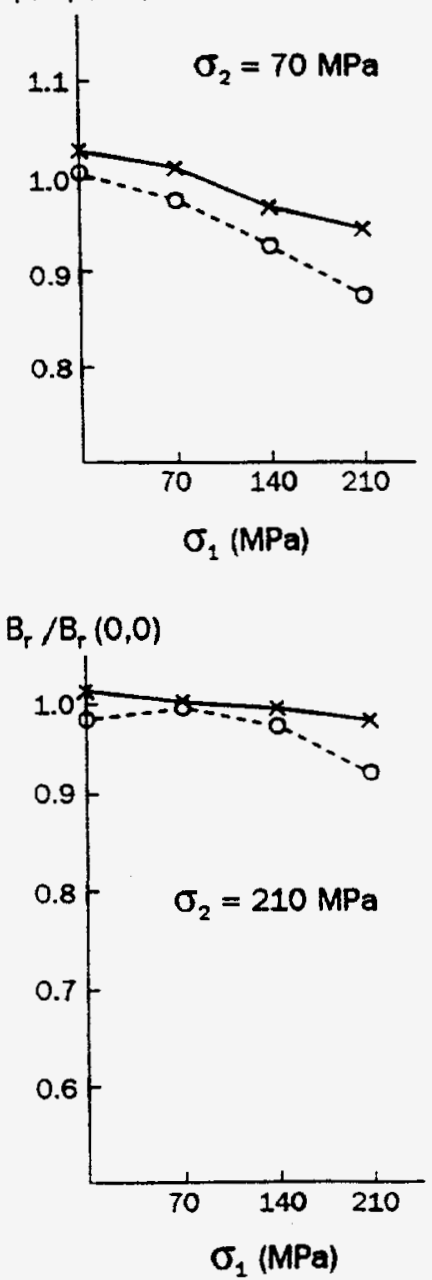

Figure 3. Comparison between model and experiment Figure 4. Comparison between model and experiment of normalized remanence values when the field is parallel to the $\sigma_{1}$-axis. of normalized remanence values when the field is parallel to the $\sigma_{2}$-axis. 
Fig. 5 displays $B_{\mathrm{r}} / \mathrm{B}_{\mathrm{r}}(0,0)$ vs. $\sigma_{1}-\sigma_{2}$ for both theory and experiment, for the two cases where $H \|$ $\sigma_{1}$-axis and $H \| \sigma_{2}$-axis. It is noted for each case that the points all fit within a band. In the case of $H \| \sigma_{1}$-axis, both model and experiment exhibit an increasing band of essentially constant positive slope at negative $\sigma_{1}-\sigma_{2}$, rising to a peak at positive $\sigma_{1}-\sigma_{2}$. The bands for model and experiment are approximately the same width. In the case of $H \| \sigma_{2}$ axis, the bands for model and experiment are again of approximately the same width, but this time the peak occurs at negative $\sigma_{1}-\sigma_{2}$, and the bands decrease in value at essentially constant negative slope at positive $\sigma_{1}-\sigma_{2}$.

Fig. 6 exhibits a more interesting result. When the difference in values $\left(B_{r} / B_{r}(0,0)\right)$ between when the field is parailel to the $\sigma_{1}$-axis and when the field is parallel to the $\sigma_{2}$-axis are plotted against the stress difference $\sigma_{1}-\sigma_{2}$, a straight line band is found, both for theory and experiment. However, band widths and slopes differ slightly, possibly due to the slight experimental liftoff variation appearing in Fig. 4 , which would affect the fits slightly.

Figure 5. Plots of $\mathrm{B}_{\mathrm{r}} / \mathrm{B}_{\mathrm{r}}(0,0)$ vs. stress difference $\sigma_{1}-\sigma_{2}$ for the various values taken by $\sigma_{1}$ and $\sigma_{2}$ (viz., $0,70,140,210 \mathrm{MPa}$ each). Both model and experiment are shown. Also, cases for $H \| \sigma_{1}$-axis and $H \| \sigma_{2}$-axis are shown.
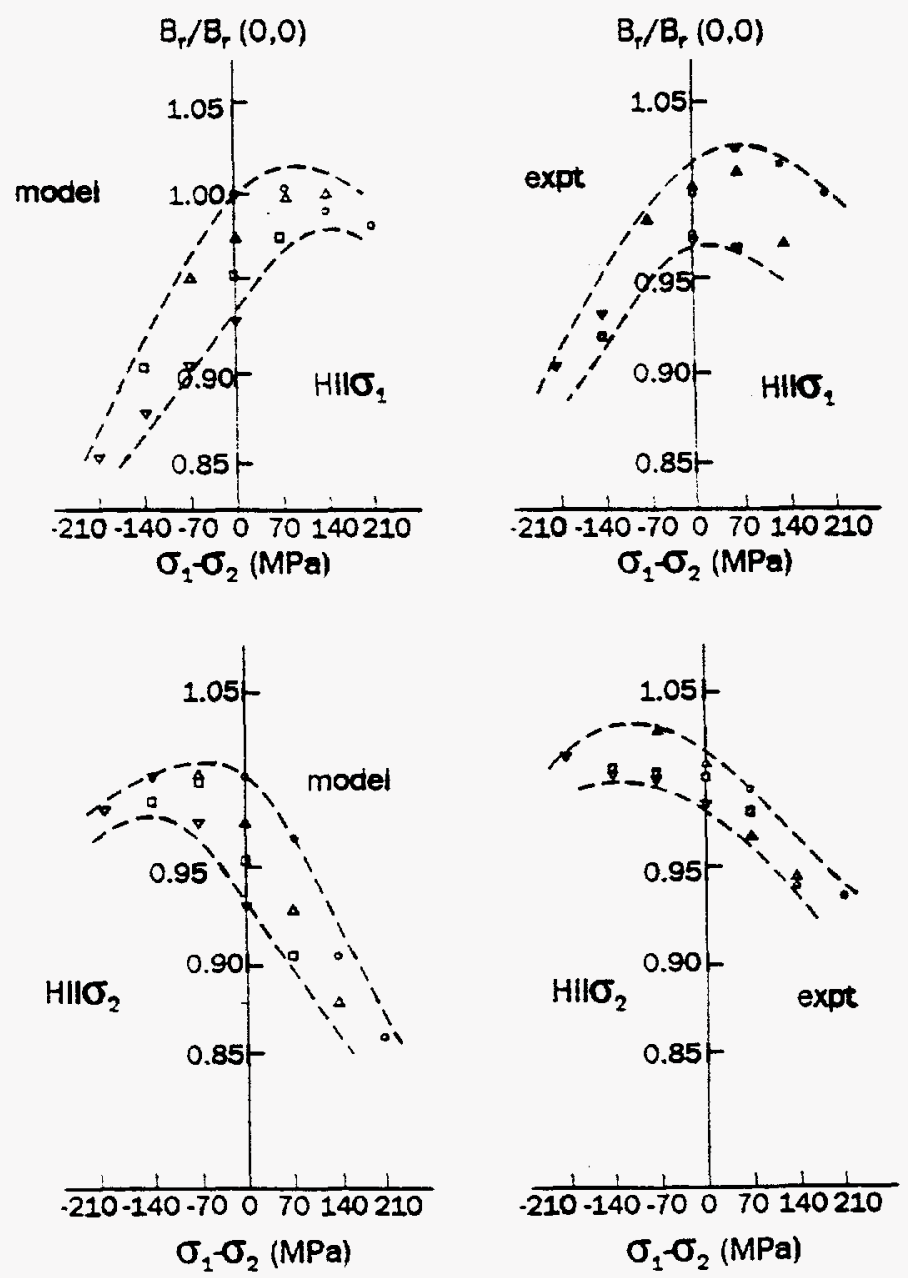

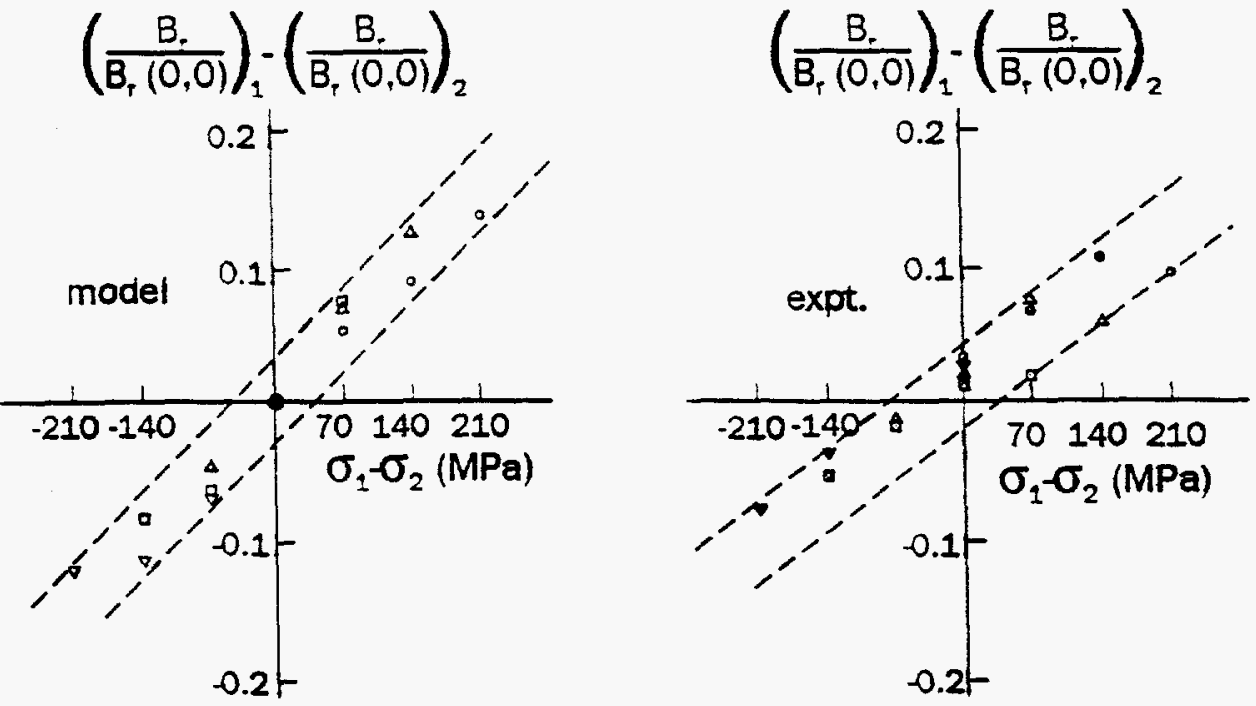

Figure 6. Differences between normalized remanence values for $H \| \sigma_{1}$-axis and $H \| \sigma_{2}$-axis plotted against $\sigma_{1}-\sigma_{2}$. Results for both model and experiment are shown.

\section{CONCLUSIONS}

That a straight-line correlation can be found between $\sigma_{1}-\sigma_{2}$ and algebraically manipulated values for magnetic properties is quite useful. It means that an NDE magnetic technique can be constructed for obtaining the biaxial stress difference $\sigma_{1}-\sigma_{2}$ to within a certain band of error.

In this case, the difference between normalized values for remanence when field is parallel to one axis and then the other can be used to determine $\sigma_{1}-\sigma_{2}$ to within a certain error range (in this case, 15 $\mathrm{ksi}(105 \mathrm{MPa})$ based on experiment and $10 \mathrm{ksi}(70 \mathrm{MPa})$ based on the model). It remains to be seen whether these error ranges can be reduced both experimentally and theoretically, or whether other magnetic properties might exhibit smaller error ranges when the same procedure is used for them.

It is anticipated that the results presented here will be expanded to other magnetic properties and to compressive stress as well as tensile stress.

\section{ACKNOWLEDGEMENTS}

Support for this work was provided by DOE Project DOE/ER/14180. Acquaintance with the Schneider model (newly modified here) arose from an earlier project with NSWC, Annapolis. 


\section{REFERENCES}

1. R. LANGMAN, "Magnetic Properties of Mild Steel Under Conditions of Biaxial Stress," IEEE Trans. on Magnetics, 26, 1246 (1990).

2. R. LANGMAN, "Measurement of the Mechanical Stress in Mild Steel by Means of Rotation of the Magnetic Field Strength — Part 2: Biaxial Stress," NDT International, 15, 91 (1982).

3. K. KASHIWAYA, H. SAKAMOTO, and Y. INOUE, "Nondestructive Measurement of Residual Stress Using Magnetic Sensors," in Proc. VI Intl. Congress on Experimental Mechanics, Society for Experimental Mechanics, Bethel, Conn, 1988, Vol 1, p. 30.

4. D.J. BUTTLE, W. DALZELL, C.B. SCRUBY and R.A. LANGMAN, "Comparison of Three Magnetic Techniques for Biaxial Stress Measurement," in Rev. Progress Quant. Nondestr. Eval., ed. D.O. Thompson and D.E. Chimenti (Plenum. NY, NY, 1990), p. 1879.

5. G.L. BURKHARDT, H. KWUN, A.E. CROUCH, and D.A. DESNOYER, "Review of Stress Measure ment Techniques for Pipelines," in Damage Assessment, Reliability and Life Prediction of Power Plant Components, PVP-vol. 193, NDE-vol.8, Proc. 1990 Pressure Vessels and Piping Conference, Nashville, TN, 1990 (ASME, NY, NY, 1990), p.95.

6. C.S. SCHNEIDER and J.M. RICHARDSON, "Biaxial Magnetoelasticity in Steels," J. Appl. Phys. 53, 8136 (1982).

7. K. KASHIWAYA, "Fundamentals of Nondestructive Measurement of Biaxial Stress in Steel Utilizing Magnetoelastic Effect Under Low Magnetic Field,” Jpn. J. Appl. Phys. 30, 2932 (1991).

8. C.S. SCHNEIDER, P.Y. CANNELL, and K.T. WATTS, "Magnetoelasticity for Large Stresses," IEEE Trans. Magn. 28, 2626 (1992). 